\title{
THE EFFECT OF SINGLE AND COMPOSITE ADDITIVES ON CD AND PB MOBILITY, SPECIATION AND ACCUMULATION IN LATE RICE (ORYZA SATIVA L.) GROWN ON CONTAMINATED SOIL
}

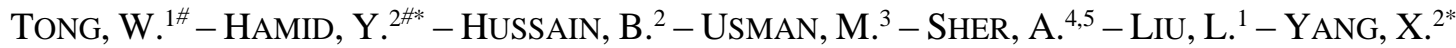 \\ ${ }^{I}$ Qiujiang Agricultural and Rural Bureau, Quzhou District, Zhejiang Province, China \\ ${ }^{2}$ Ministry of Education (MOE) Key Lab of Environ. Remediation and Ecol. Health, College of \\ Environmental and Resources Science, Zhejiang University, Hangzhou 310058, China \\ ${ }^{3}$ PEIE Research Chair for the Development of Industrial Estates and Free Zones, Center for \\ Environmental Studies and Research, Sultan Qaboos University, Al-Khoud 123, Muscat, Oman \\ ${ }^{4}$ School of Agronomy, Anhui Agricultural University, Hefei, Anhui, China \\ ${ }^{5}$ Key Laboratory of Crop Chemical Regulation and Chemical Weed Control, College of \\ Agronomy, Shanxi Agricultural University, Taigu, Shanxi, China \\ ${ }^{\#}$ These authors contributed equally to this work. \\ *Corresponding authors \\ e-mail: yasirses2007@gmail.com; xeyang@zju.edu.cn
}

(Received 29 $9^{\text {th }}$ Oct 2019; accepted $30^{\text {th }}$ Jan 2020)

\begin{abstract}
This field trial investigated the cadmium $(\mathrm{Cd})$ and lead $(\mathrm{Pb})$ immobilization in contaminated paddy soil. Five stabilizing agents including lime, biochar, phosphatic fertilizer (PF) and two composites $(\mathrm{S} 1, \mathrm{~S} 2)$ were investigated $(1 \% \mathrm{w} / \mathrm{w})$ for metals immobilization by growing late rice as a test crop. The results revealed the improved $\mathrm{pH}$ and decreased metal availability in lime, S1, biochar and S2 treated plots. The $\mathrm{Cd}$ and $\mathrm{Pb}$ speciation results depicted a decrease in exchangeable $\mathrm{Cd}$ content to less mobile forms (29 and 30\%) with addition of biochar and S1 in harvest stage samples. The exchangeable fraction of $\mathrm{Pb}$ was significantly reduced to 29, 29 and $36 \%$ with $\mathrm{S} 1, \mathrm{~S} 2$ and biochar, respectively. Moreover, $\mathrm{Cd}$ and $\mathrm{Pb}$ accumulation in rice grains was lowest in composite stabilizers and biochar treatments. Our results showed a significant increase in leaf photosynthetic rate, transpiration rate, biomass and grains yield in S1 amended plot. These lessening effects are owed to the conversion of available metal contents to the least mobile forms. Our results confirmed the effectiveness of organic additives alone and in mixture with inorganics in reducing metal mobility, improving immobilization, enhancing growth and decreasing accumulation in food parts and showed a great prospect in safer food production.
\end{abstract}

Keywords: metals immobilization, lime, biochar, phosphatic fertilizer, rice uptake

\section{Introduction}

Trace metals especially cadmium $(\mathrm{Cd})$ and lead $(\mathrm{Pb})$ have a strong toxic effect on animals and humans which exerts health concerns worldwide (Chen et al., 2018). Cd and $\mathrm{Pb}$ contamination are often reported in agricultural soils due to natural and anthropogenic activities but their entry into the soil environment is mostly associated with agricultural inputs and mining or smelting effluents (Hamid et al., 2018). Cd and $\mathrm{Pb}$ are among the most toxic metals due to their high accumulation in edible parts of plants hence posing a high risk of contamination to the food chain (Liang et al., 2016; Igalavithana et al., 2019). Therefore, it is of utmost importance to remediate metals 
polluted soils without influencing the crop yield (Xiong et al., 2019). Moreover, it is important to unveil the metals availability and related processes for the development of innovative techniques to improve metals stability in soil and reduced accumulation in plants.

In recent years, the sorption of metals with low cost and environment-friendly stabilizers has been emerged as an innovative approach to remove contaminants from polluted sites. Various inorganic or organic stabilizers have been reported for their effectiveness in immobilizing the metals in different soil types (Hamid et al., 2019b). Stabilizers metals availability owing to adsorption/stabilization/precipitation/ion exchange attributes. However, many adsorbents show disadvantages due to their less stability, adsorption capacity and success in multi metals contaminated soils (Hu et al., 2017). Moreover, in some cases single additive show effectiveness for one metal and did not present significant difference for other elements. So, composite addition of additives may be more efficient in reducing metal contamination in co-contaminated soil (Lahori et al., 2017). Our earlier reports (Hamid et al., 2019a) also confirmed the effectiveness of composite amendments on metals stability in co-contaminated soils.

Immobilization is a process of remediating the contaminants by transforming their high mobile fraction to less available form. Lime is regarded as one of the most effective immobilizer for metallic compounds (Bade et al., 2012). Liming the polluted region points to reduced metal availability by increasing soil $\mathrm{pH}$ and the production of hydroxyl ions due to hydrolysis of $\mathrm{CaCO}_{3}$ (Wu et al., 2016). Liming induces metals availability by making carbonate-metal precipitates which reduces the exchangeable fraction of metals (Singh and Kalamdhad, 2013). In a field experiment, Rehman et al. (2017a) reported a decrease in available Cd contents with a combined addition of lime and biochar. Recently, in-situ stabilization of metal contaminated soils with phosphatic fertilizer has gained keen attention as an alternative remediation technique. Phosphate induced stabilization comprises of metals precipitation with inorganic phosphate or metals adsorption (Hong et al., 2008, 2010). Phosphatic fertilizers addition can alleviate soil characteristics such as $\mathrm{pH}$, available phosphate contents, soil surface charge or directly interacts with metal ions in the soil. These changes can induce a swing in the metal available form to a more stable form (Zhao et al., 2014; Yan et al., 2015).

Biochar is an organic material pyrolyzed at different temperatures under low oxygenic conditions (Leng et al., 2019) by combustion of wood, plant residues etc. Biochar is a stable compound mainly used in the restoration of metal contaminated sites. Biochar has ability to retain metals owing to complexation, adsorption or ion exchange mechanisms (El-Naggar et al., 2018). Biochar addition improved the plant growth by increasing nutrients availability and reducing leaching in soil (Cornelissen et al., 2018; Li et al., 2019). Meanwhile, metals adsorption on the surface of biochar depends upon raw material, metal concentration and pyrolysis temperature. An improved stability of biochar with high combustion temperature is reported in literature (Song et al., 2012; Bashir et al., 2018).

To date, different inorganic and organic additives have been adopted in stabilization of metal but most of the studies focused on single contaminant and rarely on multimetal contamination. Therefore, there is a shortage of studies focusing on stabilization of multi -metal contamination with composite treatments and the comparison of effectiveness with their commercial competitors. Moreover, this study was established 
on improved $\mathrm{Cd}$ and $\mathrm{Pb}$ immobilization with the incorporation of single and composite additives by increasing soil $\mathrm{pH}$ and CEC. The objective of our study was (a) to check the efficacy of inorganic and organic amendments alone and their novel mixtures on improved rice biomass and grains yield, (b) to examine the availability of $\mathrm{Cd}$ and $\mathrm{Pb}$ and subsequent uptake or accumulation by late rice, (c) to gain the insights of immobilization mechanisms by speciation method, (d) to identify the most favorable soil amendment for safer food production on $\mathrm{Cd}-\mathrm{Pb}$ co-contaminated site.

\section{Materials and methods}

\section{Study site, additives collection and application}

This field experiment was conducted in a contaminated red paddy field situated in Qujiang County (E 119.01, N 29.05), Zhejiang province, China having annually mean temperature $\left(17^{\circ} \mathrm{C}\right)$ and precipitation $(1,723 \mathrm{~mm}) . \mathrm{Cd}$ and $\mathrm{Pb}$ contents of studied soil ranged to $0.54 \mathrm{mg} \mathrm{kg}^{-1}$ and $95.42 \mathrm{mg} \mathrm{kg}^{-1}$ respectively (Cao et al., 2019). Late rice cultivar (Yong You 9) was cultured in mid-July (15-07-2017) and three-week (07-082017) old seedlings were shifted to the field. This late rice cultivar is been widely used in this specific area due to its high grains production and improved biomass. Lime, biochar, PF (phosphatic fertilizer), organic manure, wood powder, sepiolite, and zeolite were collected from different commercial sources. Biochar used in this experiment was pyrolyzed from coconut shell at $350{ }^{\circ} \mathrm{C}$. Six treatments including control, lime, biochar, PF, S1 and S2 were investigated for their effectiveness as immobilizers. S1 and S2 were cycled by mixing various organic and inorganic additives with clay minerals at different ratios. S1 was derived by mixing biochar with lime, sepiolite and zeolite while S2 was composited by manual mixing of manure with lime and sepiolite. Amendments were applied in triplicates and were arrayed according to RCBD (randomized complete block design) with each plot having area $64 \mathrm{~m}^{2}$. Each treatment block was separated with ridges and includes separate inlet and outlet for watering and drainage. All the treatments were applied at $1 \%(\mathrm{w} / \mathrm{w})$ before 20 days (18-07-2017) of seedling transplantation and were mixed mechanically on the upper layer of soil. Fertilization was completed by adding $\mathrm{N}\left(130 \mathrm{~kg} \mathrm{ha}^{-1}\right), \mathrm{P}_{2} \mathrm{O}_{5}\left(50 \mathrm{~kg} \mathrm{ha}^{-1}\right)$ and $\mathrm{K}_{2} \mathrm{O}\left(150 \mathrm{~kg} \mathrm{ha}^{-1}\right)$ in shape of urea, di-ammonium phosphate and muriate of potash before start of experiment. Additional phosphatic fertilizer was not added in the treatment of PF due to its use as a stabilizing agent. Photosynthetic rate $(\mathrm{Pn})$ and transpiration rate $(\mathrm{Tr})$ were measured using an IRGA (infrared gas analyzer) after 70 days of crop growth.

\section{Soil and plant sampling}

Soil samples were collected from experimental site for $\mathrm{pH}$, organic carbon, and total metal concentration in soil (Table 1). Furthermore, for available metal contents soil sampling was done after the addition of soil additives. Samples were taken 1 day before nursery transplantation (zero month) in the field and at harvest (2017-11-10).

Meanwhile, plants were harvested at maturity and plant height, biomass and grains yield were measured. From each plot, plants were harvested $\left(1 \mathrm{~m}^{2}\right)$ and weighed for biological yield. Harvested fifteen plants were sampled and brought to the lab for metal analysis. Plants were cut into pieces (roots, shoots and grains), washed with tap water, and then rinsed with ultra-pure water. Plants were oven dried until constant weight, grinded and analyzed for metal accumulation in different parts. 
Table 1. Physico-chemical properties of soil and applied additives

\begin{tabular}{c|c|c|c|c|c}
\hline No. & Treatment/soil & $\mathbf{p H}$ & $\begin{array}{c}\text { Organic carbon } \\
\left(\mathbf{g ~ k g}^{-1}\right)\end{array}$ & $\begin{array}{c}\text { Total Pb } \\
\left(\mathbf{m g ~ k g}^{-1}\right)\end{array}$ & $\begin{array}{c}\text { Total Cd } \\
\left(\mathbf{m g ~ k g}^{-1}\right)\end{array}$ \\
\hline 1 & Soil & 5.71 & 54.76 & 95.42 & 0.54 \\
2 & Lime & 11.12 & nd & 0.624 & 0.20 \\
3 & Biochar & 8.06 & 387 & 1.656 & 0.05 \\
4 & PF & 7.21 & nd & 2.57 & 0.35 \\
5 & S1 & 11.12 & 74.68 & 4.800 & 0.20 \\
6 & S2 & 11.34 & 32.11 & 3.895 & 0.15 \\
\hline
\end{tabular}

Soil with silty clay texture (Sand $15 \%$, Silt $32.10 \%$, Clay $52.90 \%$ ) PF: Phosphatic fertilizer, S1 and S2 (stabilizers)

\section{Amendments, soil and plant analysis}

Basic physicochemical properties of soil and amendments were measured with standard methods proposed by ( $\mathrm{Li}, 2000$; Bao, 2008). Amendments and soil pH were measured by shaking material and water at ratio 1: 2.5 using a PB-10, Sartorius, Germany $\mathrm{pH}$ meter (Table 1). Total metal concentration in additives and soil was measured by digesting the material with a solution of $\mathrm{HNO}_{3}-\mathrm{HF}-\mathrm{HClO}_{4}$ for $12 \mathrm{~h}$. DTPA extraction was performed to analyze available $\mathrm{Cd}$ and $\mathrm{Pb}$ concentration in treated soil. Soil $(20 \mathrm{~g})$ was shaken with a DTPA-TEA mixture $(50 \mathrm{~mL})$ for $2 \mathrm{~h}$ at room temperature. Suspension was then filtered from $0.45-\mu \mathrm{m}$ filter and bio-available $\mathrm{Cd}$ and $\mathrm{Pb}$ concentration in solution was calculated using ICP-MS (Agilent, 7500a, USA) (Li, 2000; Bao, 2008).

$\mathrm{Cd}$ and $\mathrm{Pb}$ fractionation in treated and untreated soil at harvest were estimated by the sequential extraction method (Table 2) proposed by (Tessier et al., 1979).

Dried and grounded plant samples were digested for accumulated $\mathrm{Cd}$ and $\mathrm{Pb}$ concentration in different parts. $\mathrm{Cd}$ and $\mathrm{Pb}$ concentration were measured by digesting $0.20 \mathrm{~g}$ of desired plant sample with an acidic solution of $\mathrm{HClO}_{4}$ and $\mathrm{HNO}_{3}$ at $170{ }^{\circ} \mathrm{C}$ for $4 \mathrm{~h}$. Metals concentration in the digested solution was measured with ICP-MS (Bao, 2008).

Table 2. The sequential extraction procedure for $\mathrm{Cd}$ and $\mathrm{Pb}$

\begin{tabular}{|c|c|}
\hline Fraction & Procedure \\
\hline F1: Exchangeable & $\begin{array}{l}1 \mathrm{~g} \text { soil (treated/untreated) shaken with } 8 \mathrm{ml} \text { of } 1 \mathrm{M} \mathrm{MgCl}_{2} \text { solution } \\
\qquad(\mathrm{pH}=7)\end{array}$ \\
\hline F2: Carbonate bound & F1 residues extracted with $\mathrm{NaOAc}(1 \mathrm{M}), \mathrm{pH}: 5$ for $5 \mathrm{~h}$ \\
\hline F3: Fe-Mn oxide bound & $\begin{array}{l}\text { Residues of } \mathrm{F} 2 \text { were mined with } 20 \mathrm{~mL}(0.04 \mathrm{M}) \mathrm{NH}_{2} \mathrm{OH} \cdot \mathrm{HCl} \text { in } 25 \% \\
\qquad \mathrm{CH}_{3} \mathrm{COOH} \text { for } 6 \mathrm{~h} \text { at } 96^{\circ} \mathrm{C}\end{array}$ \\
\hline F4: Organic matter bound & $\begin{array}{c}\text { Firstly, } \mathrm{F} 3 \text { residues shaken with } 5 \mathrm{~mL} \text { of } \mathrm{H}_{2} \mathrm{O}_{2}(30 \%) \text { for } 3 \mathrm{~h}\left(\text { at } 85^{\circ} \mathrm{C}\right) \text { and } \\
\text { then with } 3.2 \mathrm{M} \text { ammonium acetate for half an hour and mixture was } \\
\text { collected and mixed to make one solution }\end{array}$ \\
\hline F5: Residual & Remaining residues were digested with $\mathrm{HNO}_{3}-\mathrm{HF}-\mathrm{HClO}_{4}$ and diluted \\
\hline
\end{tabular}

Cadmium and $\mathrm{Pb}$ translocation factor (TF) from roots to shoot was calculated with the following formula (Eq. I): 


\section{Statistical analyses}

All the used chemicals and reagents in this experiment were of analytic grade. The digestion tubes were washed with distilled water, put overnight in acidic solution and again washed with distilled water followed by rinsing with ultra-pure water before each use. Data presented are means of three replicates \pm S.E which was estimated with MS Excel 2007. Statistical analysis (LSD test) was performed with SPSS 20.0 and graphical illustration was done with Origin Pro 8.0.

\section{Results}

\section{Effect of applied passivators on soil $\mathrm{pH}$ and DTPA extractable Cd and Pb at different time intervals}

The effect of applied additives on soil $\mathrm{pH}$ at zero month and harvest is presented in Figure 1. Zero month samples were taken around 20 days of amendments. There was a quick elevation in soil $\mathrm{pH}$ with lime and $\mathrm{S} 2$ treatment at zero month. Lime and $\mathrm{S} 2$ treatment showed an increase of 1.68 and 0.93 units in soil $\mathrm{pH}$ as compared to control. Meanwhile, a significant increase in soil $\mathrm{pH}$ with lime, S2, biochar and S1 was also observed at harvest samples. These treatments improved soil $\mathrm{pH}$ to a significant level with values of $7.56,6.84,6.71$ and 6.53 respectively as compared to respective control (5.8). It was noteworthy; that addition of PF did not improv the soil $\mathrm{pH}$ at both sampling stages and showed slightly acidic behavior. Cd availability (DTPA extractable) was reduced with biochar and composite mixtures (S1 and S2) (Fig. 2). Composite treatment (S2) showed a significant reduction in Cd availability at zero month while, $\mathrm{S} 1$ and biochar were effective in reducing metal availability in harvest stage samples. Maximum Cd was extracted in control treatment at both sampling stages $(0.374$ and $\left.0.357 \mathrm{mg} \mathrm{kg}^{-1}\right)$. When compared with the control, $\mathrm{S} 1$ treatment and biochar significantly $(p<0.05)$ reduced the DTPA extractable Cd by 63 and 60\% respectively in the second sampling stage. Application of treatments reduced the DTPA extractable $\mathrm{Cd}$ in following order $\mathrm{S} 1 \approx$ biochar $>\mathrm{S} 2 \approx$ lime $>\mathrm{PF}>$ control.

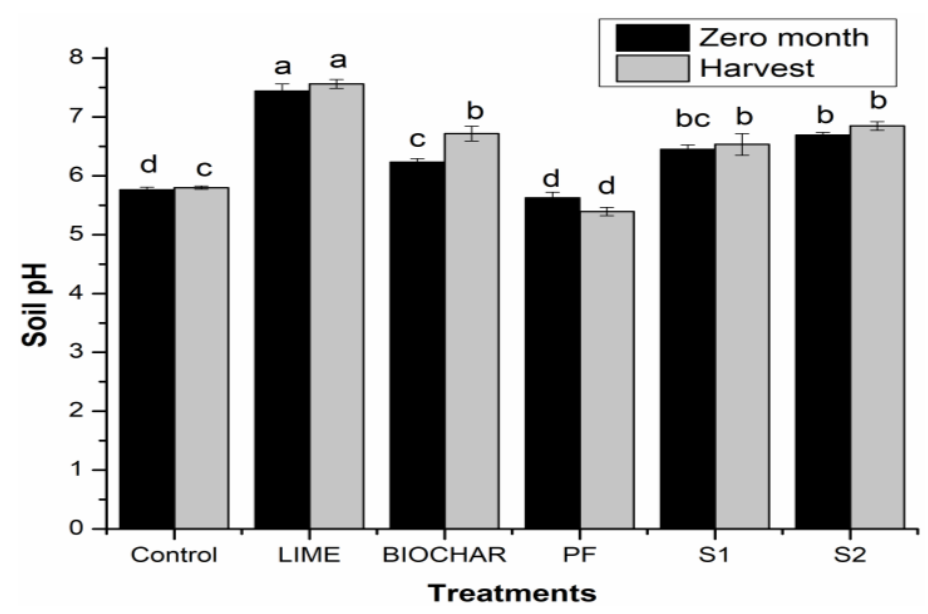

Figure 1. Effect of soil amendments on soil pH at different time intervals. Control, lime, biochar, PF, S1 and S2 were employed in triplicates $(1 \% \mathrm{w} / \mathrm{w})$. Error bars with different letters show significance at different sampling time 

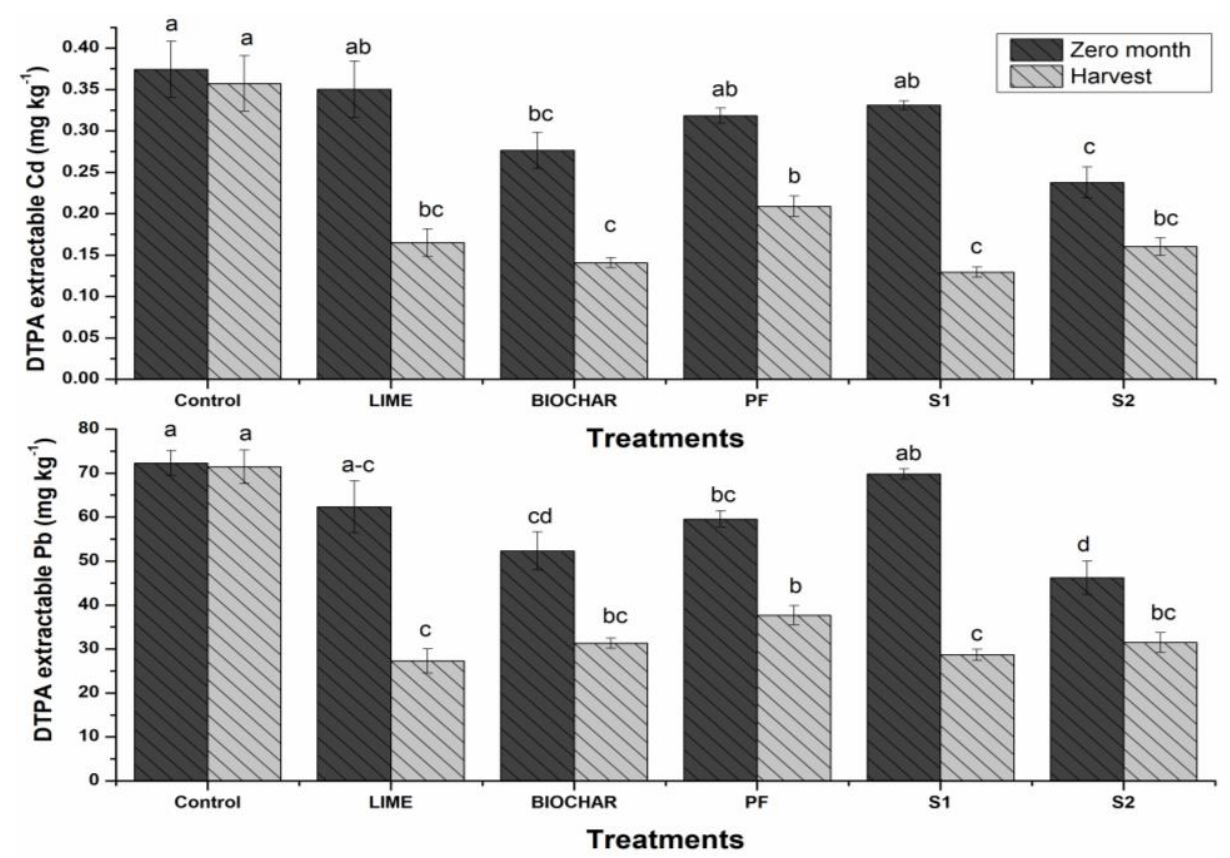

Figure 2. Effect of soil additives on available $C d$ and Pb contents of contaminated soil. Control, lime, biochar, PF, S1 and S2 were employed in triplicates (1\% w/w). Error bars with different letters show significance at different sampling time

Meanwhile, alone lime and its combination with organic and clay additives (S1) reduced the $\mathrm{Pb}$ extractability by 61 and $59 \%$ as compared to respective control in harvesting stage soil samples. Biochar treatment also signifies the reduction in $\mathrm{Pb}$ extraction in comparison with control by decreasing $\mathrm{Pb}$ availability by $56 \%$. Generally, all the applied treatments significantly improved the metals immobilization by decreasing metal mobility and extraction at end of experiment. $\mathrm{Pb}$ availability with applied treatments reduced in subsequent order $\mathrm{S} 1 \approx$ lime $>\mathrm{S} 2 \approx$ biochar $>\mathrm{PF}>$ as compared to control.

\section{Correlation between soil $\mathrm{pH}$ and DTPA extractable Cd and Pb at different time intervals}

A negative linear correlation was found between soil $\mathrm{pH}$ and DTPA extractable $\mathrm{Cd}$ and $\mathrm{Pb}$ at zero month and harvesting stage samples (Fig. 3). Correlation between available $\mathrm{Cd}$ and soil $\mathrm{pH}$ at both sampling stages showed negative behavior $\left(\mathrm{R}^{2}=0.0027, \mathrm{p}=0.837\right.$ and $\left.\mathrm{R}^{2}=0.0182, \mathrm{p}=0.594\right)$. Meanwhile, amendments addition resulted in a significant negative correlation between soil $\mathrm{pH}$ and available $\mathrm{Pb}$ contents in zero month and harvest samples $\left(\mathrm{R}^{2}=0.2851, \mathrm{p}=0.022\right.$ and $\left.\mathrm{R}^{2}=0.3147, \mathrm{p}=0.015\right)$.

\section{Cd and $\mathrm{Pb}$ species distribution with applied additives}

The chemical speciation of $\mathrm{Cd}$ and $\mathrm{Pb}$ in zero month and harvest soil samples is summarized in Figure 4. The applied treatments showed little difference for $\mathrm{Cd}$ portioning at zero month soil samples with maximum exchangeable $\mathrm{Cd}$ in control treatments $(58 \%)$ and lowest in biochar treated blocks (41\%). During the experiment, $\mathrm{Cd}$ quantities for different species varied with amendments. In general, exchangeable Cd content decreased with an increase in carbonate, oxide, organic bound and residual 
fractions. Biochar treatments reduced the Cd exchangeability to $29 \%$ followed by $\mathrm{S} 1$ (30\%), PF (32\%), S2 (33\%) and lime (37\%) as compared to control (50\%). The effect of treatments on $\mathrm{Pb}$ mobility and partitioning showed the effectiveness of composite treatments and biochar at the experiment end. $\mathrm{Pb}$ exchangeable fraction was decreased to $29 \%$ each for S2 and S1 followed by biochar (36\%), PF (38\%) and lime (40\%) in comparison with control (63\%).
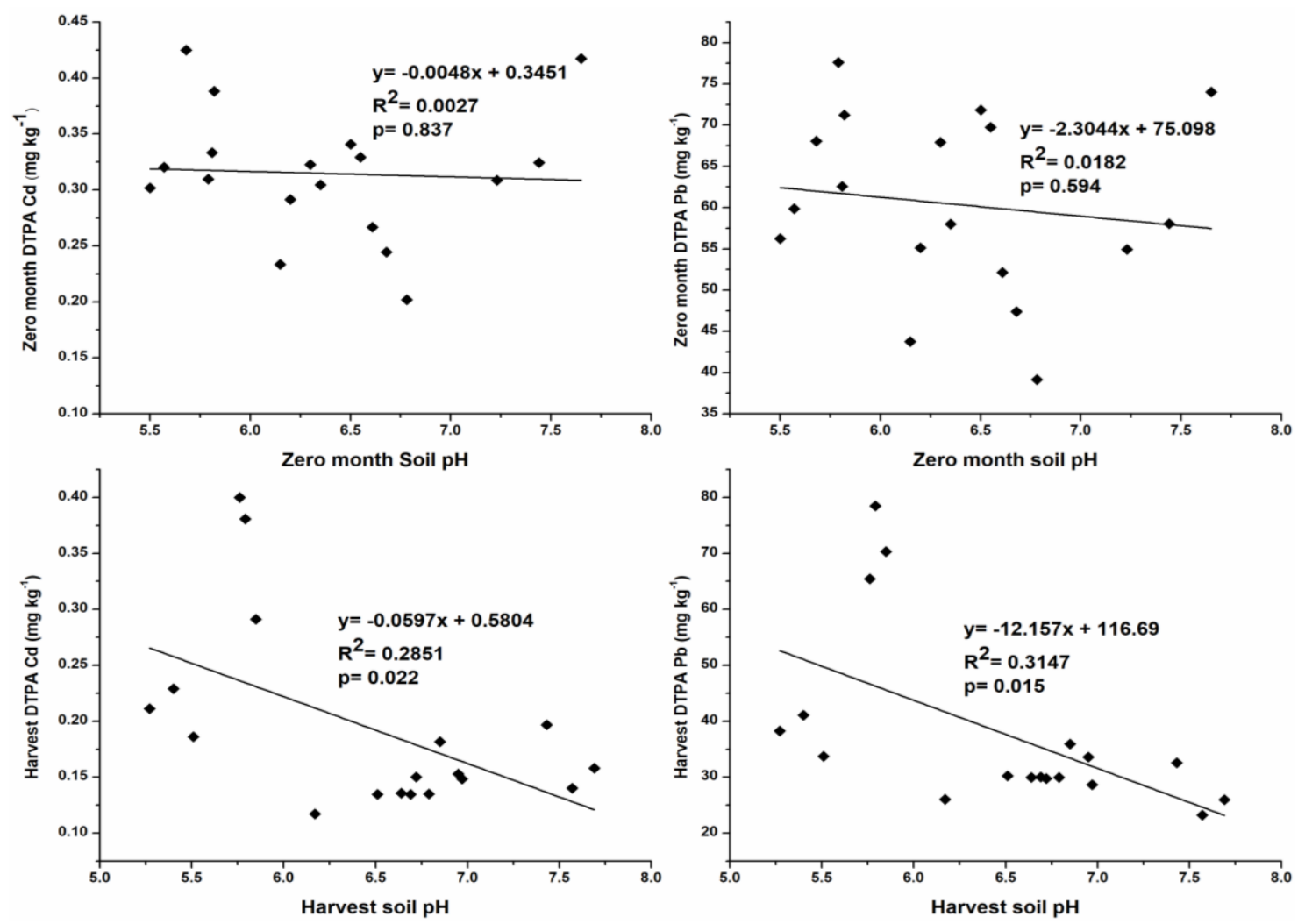

Figure 3. Correlation between soil $\mathrm{pH}$ and available $\mathrm{Cd}$ and $\mathrm{Pb}$ contents of contaminated soil

\section{Effect of applied additives on gaseous exchange}

All the applied treatments significantly increased the photosynthetic rate $(\mathrm{Pn})$ of rice (Fig. 5). Photosynthetic rate increased in S2 followed by S1 which increased up to 112 and $102 \%$ as compared to control. Biochar, PF and lime also showed significant increase in photosynthetic rate by 85,82 and $75 \%$ respectively as compared to the control. Maximum increase in transpiration rate ( $\mathrm{Tr}$ ) was witnessed in S2 and S1 treated plots which was $162 \%$ and $152 \%$ higher than control (Fig. 5). On the other side, biochar, PF and lime also significantly improved the $\operatorname{Tr}$ by 124, 118 and $93 \%$ respectively, compared to control.

\section{$C d$ and $P b$ accumulation in plant parts}

Uptake and accumulation of $\mathrm{Cd}$ and $\mathrm{Pb}$ in rice were significantly affected by treatments (Table 3). At maturity all the applied treatments significantly reduced Cd contents in rice roots compared to the control but there was no significant difference among applied additives for $\mathrm{Cd}$ accumulation in roots. Adding $\mathrm{S} 2$ and biochar 
significantly reduced the shoots $\mathrm{Cd}$ concentration by reducing uptake to 0.216 and $0.227 \mathrm{mg} \mathrm{kg}^{-1}$ as compared to the control $\left(0.322 \mathrm{mg} \mathrm{kg}^{-1}\right)$. Moreover, Cd content in rice grains was reduced to 0.049 and $0.056 \mathrm{mg} \mathrm{kg}^{-1}$ in S2 and biochar treatments with the highest in control $\left(0.231 \mathrm{mg} \mathrm{kg}^{-1}\right)$. On the other hand, $\mathrm{Pb}$ accumulation in rice grains was significantly reduced with $\mathrm{S} 2, \mathrm{~S} 1$ and biochar treatment $(0.070,0.101$ and $\left.0.126 \mathrm{mg} \mathrm{kg}^{-1}\right)$ respectively which was much less than control $\left(1.818 \mathrm{mg} \mathrm{kg}^{-1}\right)$. Lime and $\mathrm{PF}$ treatments also significantly reduced $\mathrm{Pb}$ accumulation in rice grains with values of 0.395 and $0.922 \mathrm{mg} \mathrm{kg}^{-1}$.

Translocation of $\mathrm{Cd}$ and $\mathrm{Pb}$ from roots to shoots is presented in Figure 6. There was no significant difference for roots to shoots $\mathrm{Cd}$ translocation among the treatments with minimum translocation in $\mathrm{S} 1(62 \%)$ followed by lime $(65 \%)$. While, $\mathrm{Pb}$ translocation in shoots was significantly reduced with biochar and S2 treatments (20\% and 29\%), as compared to control.

Table 3. Effect of soil additives on metal contents of late rice

\begin{tabular}{c|c|c|c|c|c|c}
\hline \multirow{2}{*}{ Treatments } & \multicolumn{3}{|c|}{ Cd concentration $\left(\mathbf{m g ~ k g}^{-1}\right)$} & \multicolumn{3}{c}{ Pb concentration $\left(\mathbf{m g ~ k g}^{-1}\right)$} \\
\cline { 2 - 7 } & Roots & Shoots & Grains & Roots & Shoots & Grains \\
\hline Control & $0.462 \pm 0.038 \mathrm{a}$ & $0.322 \pm 0.022 \mathrm{a}$ & $0.231 \pm 0.011 \mathrm{a}$ & $61.10 \pm 2.61 \mathrm{a}$ & $45.26 \pm 0.590 \mathrm{a}$ & $1.818 \pm 0.045 \mathrm{a}$ \\
Lime & $0.362 \pm 0.023 \mathrm{~b}$ & $0.238 \pm 0.012 \mathrm{bc}$ & $0.115 \pm 0.015 \mathrm{c}$ & $45.59 \pm 0.807 \mathrm{bc}$ & $20.80 \pm 1.732 \mathrm{~b}$ & $0.395 \pm 0.108 \mathrm{c}$ \\
Biochar & $0.328 \pm 0.008 \mathrm{~b}$ & $0.227 \pm 0.007 \mathrm{c}$ & $0.056 \pm 0.018 \mathrm{~d}$ & $40.34 \pm 1.277 \mathrm{c}$ & $8.20 \pm 0.508 \mathrm{~d}$ & $0.126 \pm 0.019 \mathrm{~d}$ \\
PF & $0.366 \pm 0.041 \mathrm{~b}$ & $0.276 \pm 0.012 \mathrm{~b}$ & $0.177 \pm 0.011 \mathrm{~b}$ & $48.02 \pm 1.001 \mathrm{~b}$ & $21.50 \pm 0.699 \mathrm{~b}$ & $0.922 \pm 0.026 \mathrm{~b}$ \\
S1 & $0.369 \pm 0.015 \mathrm{~b}$ & $0.231 \pm 0.016 \mathrm{bc}$ & $0.119 \pm 0.010 \mathrm{c}$ & $40.97 \pm 2.21 \mathrm{c}$ & $18.35 \pm 0.629 \mathrm{~b}$ & $0.101 \pm 0.013 \mathrm{~d}$ \\
S2 & $0.314 \pm 0.002 \mathrm{~b}$ & $0.216 \pm 0.007 \mathrm{~d}$ & $0.049 \pm 0.011 \mathrm{~d}$ & $45.19 \pm 1.06 \mathrm{bc}$ & $13.40 \pm 1.386 \mathrm{c}$ & $0.070 \pm 0.028 \mathrm{~d}$ \\
\hline
\end{tabular}

Control, lime, biochar, PF, S1 and S2 were employed in triplicates $(1 \% \mathrm{w} / \mathrm{w})$. Different letters indicates significantly different values at 5\% significance level. All treatments including control receive recommended dose of N, P and K except treatment PF in which phosphorus was not applied. PF: phosphatic fertilizer, S1 and S2 (stabilizers)
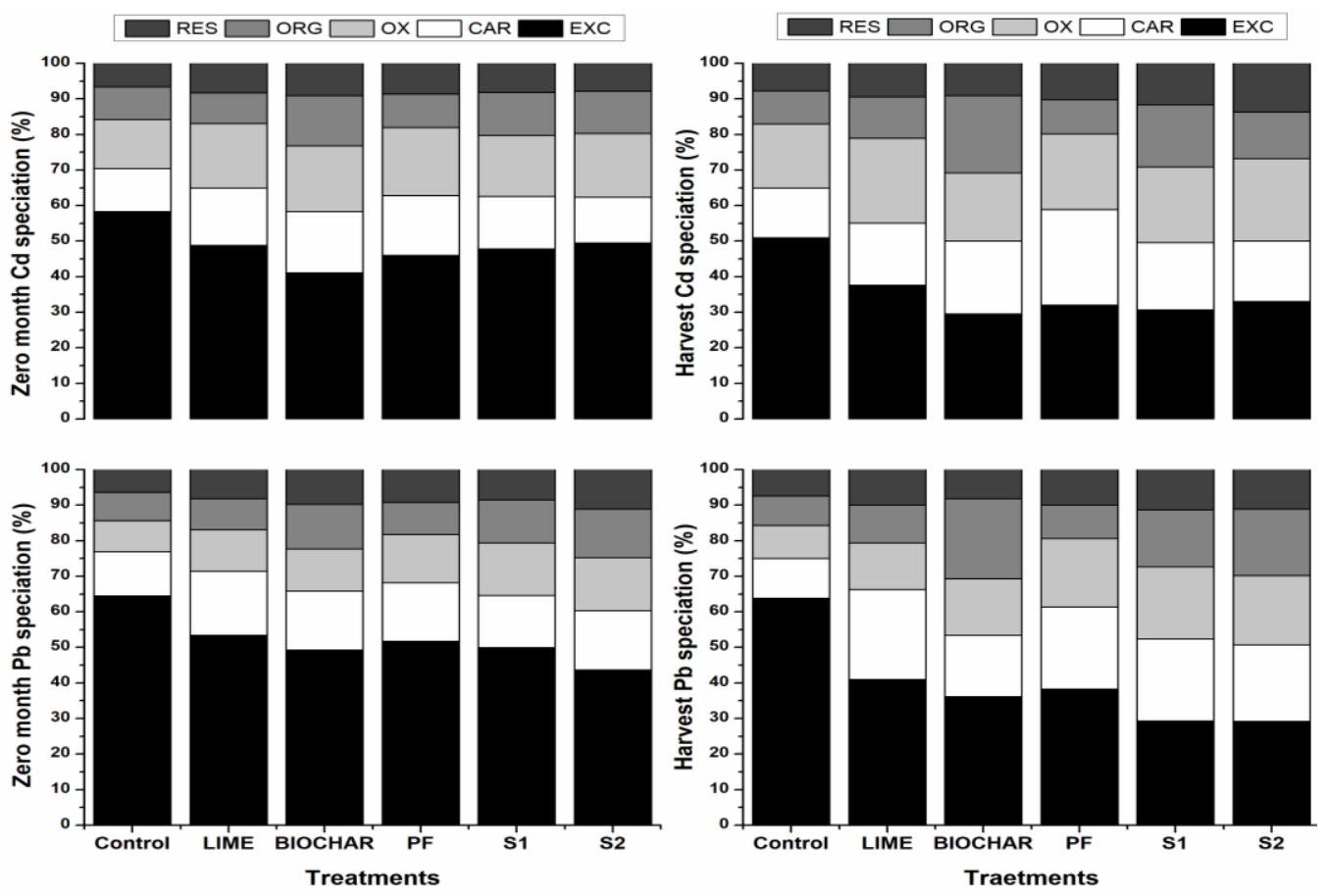

Figure 4. Effect of soil additives on $\mathrm{Cd}$ and $\mathrm{Pb}$ speciation of contaminated soil 

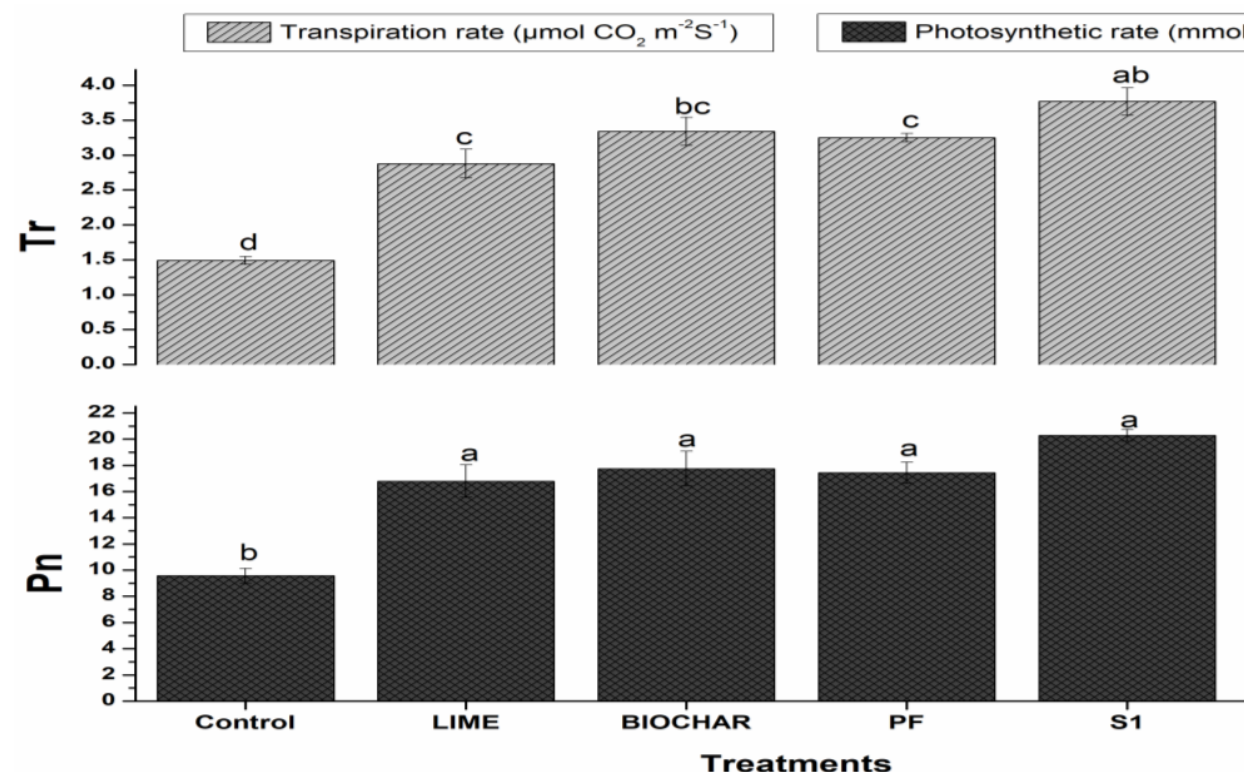

a

Figure 5. Effect of soil additives on leaf photosynthesis and yield parameters of late rice. Control, lime, biochar, PF, S1 and S2 were employed in triplicates $(1 \% \mathrm{w} / \mathrm{w})$. Error bars with different letters show significance at different sampling time

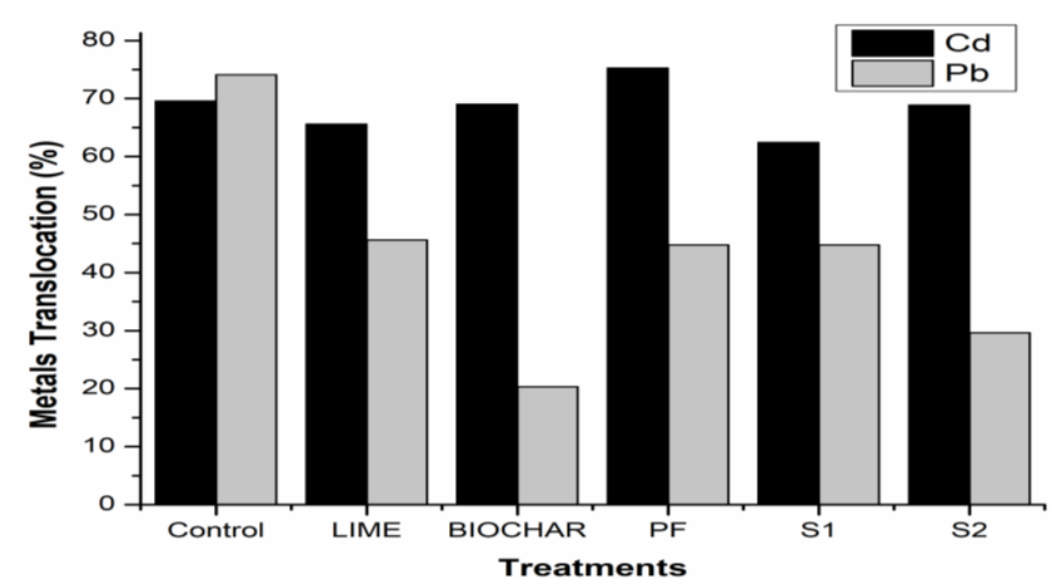

Figure 6. Effect of soil additives on metals translocation from roots to shoots. Control, lime, biochar, PF, S1 and $S 2$ were employed in triplicates $(1 \% \mathrm{w} / \mathrm{w})$

\section{Effect of additives on the growth of late rice}

Rice biomass was determined at harvest and results revealed that all the additives significantly improved rice biological yield (Table 4). But there was no significant difference for biomass yield among the additives. Maximum rice biomass was found in S1 followed by PF, S2, biochar and lime (18342, 18000, 17931, 17903, 17600, $\left.14666 \mathrm{~kg} \mathrm{ha}^{-1}\right)$. All the treatments significantly increased grains yield but maximum per hectare grains yield was observed in S1 $\left(7530 \mathrm{~kg} \mathrm{ha}^{-1}\right)$ followed by S2 and biochar (7129 and $7026 \mathrm{~kg} \mathrm{ha}^{-1}$ ) which was a significant increase as compared to control. A similar pattern was observed in plant height where all applied treatments significantly improved plant height but with no obvious difference among the additives. 
Table 4. Effect of soil additives on growth of late rice

\begin{tabular}{c|c|c|c}
\hline Treatments & Biomass $\left(\right.$ Kg ha $\left.^{-1}\right)$ & Grains yield $\left(\right.$ Kg ha $\left.^{-1}\right)$ & Plant height $(\mathbf{c m})$ \\
\hline Control & $14666 \pm 240 \mathrm{~b}$ & $6040 \pm 247 \mathrm{c}$ & $93 \pm 1.453 \mathrm{~b}$ \\
Lime & $17600 \pm 351 \mathrm{a}$ & $6741 \pm 274 \mathrm{~b}$ & $102 \pm 2.185 \mathrm{a}$ \\
Biochar & $17903 \pm 250 \mathrm{a}$ & $7026 \pm 241 \mathrm{ab}$ & $104 \pm 2.081 \mathrm{a}$ \\
PF & $18000 \pm 568 \mathrm{a}$ & $7022 \pm 98 \mathrm{ab}$ & $106 \pm 2.962 \mathrm{a}$ \\
S1 & $18342 \pm 218 \mathrm{a}$ & $7530 \pm 132 \mathrm{a}$ & $103 \pm 1.763 \mathrm{a}$ \\
S2 & $17931 \pm 470 \mathrm{a}$ & $7129 \pm 82 \mathrm{ab}$ & $104 \pm 1.701 \mathrm{a}$ \\
\hline
\end{tabular}

Control, lime, biochar, PF, S1 and S2 were employed in triplicates (1\% w/w). Different letters indicates significantly different values at 5\% significance level. All treatments including control receive recommended dose of $\mathrm{N}, \mathrm{P}$ and $\mathrm{K}$ except treatment $\mathrm{PF}$ in which phosphorus was not applied. PF: Phosphatic fertilizer, S1 and S2 (stabilizers)

\section{Discussion}

In this field experiment, the effect of several soil additives on metal translocation and accumulation was trialed out by growing paddy rice. Amendments application showed a linear increase in soil $\mathrm{pH}$. Our results found that maximum increase in soil $\mathrm{pH}$ was obtained with lime application. Previously, studies have reported an increased soil $\mathrm{pH}$ with the lime treatment (Shaha et al., 2012). Liming in the contaminated soil increased soil $\mathrm{pH}$ through release of hydroxyl group by hydrolysis mechanism. Our results are in line with Shi et al. (2019) that increase in lime application increased soil pH even under flooded conditions. Effect of lime treatment in increased soil $\mathrm{pH}$ was also reported which may cause metals precipitation or adsorption on soil, leading to decreased mobility (Mahar et al., 2015; Yan-bing et al., 2017).

Biochar, lime and their composites reduced the metal availability at both stages. Amending the contaminated soils with biochar can reduce metals availability by mattermetal complex (Shen et al., 2017). Recent experiments have shown the potential of biochar in reducing metal bioavailability because of porous structure, high $\mathrm{pH}$ and CEC and dynamic functional groups (Sui et al., 2018; Qiu et al., 2018). Biochar addition alters soil $\mathrm{pH}$ resulting in metals precipitation and adsorption on biochar surface. Ability of biochar to bind metals is attributed to different chemical or physical binding or direct sorption on biochar surface (Cornelissen et al., 2018; Schweizer et al., 2018). A lowcost amendment (lime) can retain metals in contaminated soil by reducing their availability. An increase in soil $\mathrm{pH}$ with lime treatment may cause an elevation in soil $\mathrm{pH}$ further reducing metal extractability due to adsorption or complexing processes (Chen et al., 2016b). Lime addition can improve carbonate and $\mathrm{Fe}$ or $\mathrm{Mn}$ oxide bound metals that decreased the metal contents in plant tissues (Zhu et al., 2010). The Addition of $\mathrm{CaCO}_{3}$ as liming material considerably reduced the acidic effect and favored the metal precipitation (Simón et al., 2010). Meanwhile, a decrease in metal availability with the addition of $\mathrm{Ca}(\mathrm{OH})_{2}$ in contaminated soil was also reported in the literature. Composite of lime with organic materials increased soil $\mathrm{pH}$, reduced EC and improved the metals immobilization in contaminated soils (Hamid et al., 2018). Meanwhile, a good correlation was observed between available metals and soil $\mathrm{pH}$ at both stages. This correlation may be ascribed to the change in soil $\mathrm{pH}$ with applied amendments which is an important factor in regulating the availability of metals (Ma et al., 2010).

Moreover, application of soil amendments reduced the highly exchangeable fraction to least available form. It has been stated that biochar due to high surface area, CEC, 
high $\mathrm{pH}$ and active functional groups can interact with metals in reducing metals bioavailability to field crops. Stable biochar-metal complexes result in reduced metals availability in soil. A decreased $\mathrm{Cd}$ bioavailability with biochar application was reported by Li et al. (2009). Moreover, Park et al. (2011) investigated the enhanced Cd immobilization and reduced availability with chicken manure and green waste biochar. Biochar addition tends to improved oxide bound and organic bound metals by formation of precipitates and complexes (Méndez et al., 2013; Wang et al., 2014).

Photosynthetic and transpiration rate were higher in amended blocks as compared to control treatment. Our findings are in line with Tian et al. (2011), who reported that metals toxicity negatively affected plant photosynthesis. The reduced photosynthetic activity in control may be attributed to adverse effects of metals toxicity on plants (Rehman et al., 2017b; Hamid et al., 2019c).

Changes in physical or chemical properties e.g. soil $\mathrm{pH}$ and metals availability with additives results in reduced metals accumulation and uptake by plants. In our study organic amendments in composite (S2) or alone (biochar) reduced metals accumulation in rice especially grains. Organic manure changes soil $\mathrm{pH}$ and cation exchange capacity of soil which results in improved immobilization (Dourado et al., 2013). Organic wastes have active functional groups that actively form organic-metal complexes. This complexation process might restrict metals mobility in soil and plant (Liu et al., 2015). Combined treatment of additives may increase soil $\mathrm{pH}$ and metal accumulation in plant parts. Addition of lime with sepiolite was reported for improved $\mathrm{pH}$ and reduced metal contents in the plant (Shirvani et al., 2006). Various studies have confirmed the enriched soil pH with biochar addition (Sun et al., 2014; Chen et al., 2016a). Generally, biochar induced metal stabilization includes metal-phosphate precipitates, metals adsorption, biochar-metal electro static interaction, activated functional groups and chelation (Rodríguez-Vila et al., 2015; Ok et al., 2015; Wiszniewska et al., 2016; Khan et al., 2018). These processes might have favored the reduced accumulation of metals in rice grains. This decreased translocation might be due to improved immobilization with applied additives (Hamid et al., 2018). Biochar and organic source addition helps in improved organic matter contents of soil which further improve nutrients availability and reduces metals activity by enhanced immobilization (Chen et al., 2016a; Khan et al., 2018). It is intended that findings of this field experiment can be used for in-situ metal stabilization but further studies regarding effective dose and long-term stability are still needed.

\section{Conclusion}

Amendments application increased the soil $\mathrm{pH}$ and reduced metals availability in contaminated soil. Composite treatment $\mathrm{S} 1$ and biochar were effective in reducing $\mathrm{Cd}$ and $\mathrm{Pb}$ extraction while lime application elevated the soil $\mathrm{pH}$ to a significant level. This improved metal immobilization with applied treatments is attributed to complexing, adsorption, ion exchange, and/or precipitation processes. Briefly the results of this study indicated the changes in exchangeable $\mathrm{Cd}$ fraction to more stable form with biochar application. Meanwhile, composite treatments were effective in reducing exchangeable $\mathrm{Pb}$ contents at harvest stage samples. Moreover, composite treatment S2 and biochar not only reduced the metals bio-availability but also assisted in reduced grains $\mathrm{Cd}$ and $\mathrm{Pb}$ concentration in rice grown on contaminated soil. The results of our experiment pointed out the stability of amendments in improved immobilization of toxic metals in 
contaminated soil but their effective dose rate and their effectiveness in different soil types needs to be addressed in later studies. Moreover, future trials regarding amendments' effect on the microbial community, enzymatic activity, long term metals immobilization and their effect under different moisture regimes can be elucidated.

Acknowledgments. This research was financially supported by the key project from Zhejiang Provincial Science and Technology Bureau (\#2018C02029; Ministry of Science and Technology of China (\#2016YFD0800805), and Sub-projects from Zhejiang Provincial Science and Technology Bureau (\#2015C02011-3; \#2015C03020-2), and the fundamental Research Funds for the Central Universities of China.

Conflict of interests. The authors declare that they have no conflict of interests.

\section{REFERENCES}

[1] Bade, R., Sanghwa, O., Won, S. S. (2012): Assessment of metal bioavailability in smelter-contaminated soil before and after lime amendment. - Ecotox. Environ. Safe. 80: 299-307.

[2] Bao, S. D. (2008): Soil Agricultural Chemistry Analysis Method. Third Ed. - China Agriculture Press, Beijing (in Chinese).

[3] Bashir, S., Muhammad, S., Qaiser, H., Sajid, M., Jun, Z., Qingling, F., Omar, A., Hongqing, H. (2018): Influence of organic and inorganic passivators on $\mathrm{Cd}$ and $\mathrm{Pb}$ stabilization and microbial biomass in a contaminated paddy soil. - J. Soils Sediments 18: 2948-2959. https://doi.org/10.1007/s11368-018-1981-8.

[4] Cao, X., Wang, X., Tong, W., Gurajala, H. K., Lu, M., Hamid, Y., Feng, Y., He, Z., Yang, X. (2019): Distribution, availability and translocation of heavy metals in soil oilseed rape (Brassica napus L.) system related to soil properties. - Environ. Pollut. 252: 733-741.

[5] Chen, D., Guo, H., Li, R., Li, L., Pan, G., Chang, A., Joseph, S. (2016a): Low uptake affinity cultivars with biochar to tackle Cd-tainted rice - a field study over four rice seasons in Hunan, China. - Sci. Total Environ. 541: 1489-1498.

[6] Chen, H. P., Yang, X. P., Wang, P., Wang, Z. X., Li, M., Zhao, F. J. (2018): Dietary cadmium intake from rice and vegetables and potential health risk: a case study in Xiangtan, southern China. - Sci. Total Environ. 639: 271-277.

[7] Chen, Y. C., Tuanhui, X., Qiaofeng, L., Mengiiao, L., Mingliu, Z., Mingkuang, W., Guo, W. (2016b): Effectiveness of lime and peat applications on cadmium availability in a paddy soil under various moisture regimes. - Environ. Sci. Pollut. Res. 23: 7757-7766. https://doi.org/10.1007/s11356-015-5930-4.

[8] Cornelissen, G., Jubaedah., Nurida, N. L., Hale, S. E., Martinsen, V., Silvani, L., Mulder, J. (2018): Fading positive effect of biochar on crop yield and soil acidity during five growth seasons in an Indonesian Ultisol. - Sci. Total Environ. 634: 561-568.

[9] Dourado, M. N., Martins, P. F., Quecine, M. C., Piotto, F. A., Souza, L. A., Franco, M. R., Tezotto, T., Azevedo, R. A. (2013): Burkholderia sp. SCMS54 reduces cadmium toxicity and promotes growth in tomato. - Ann. Appl. Biol. 163: 494-507.

[10] El-Naggar, A., Shaheen, S. M., Ok, Y. S., Rinklebe, J. (2018): Biochar affects the dissolved and colloidal concentrations of $\mathrm{Cd}, \mathrm{Cu}, \mathrm{Ni}$, and $\mathrm{Zn}$ and their phytoavailability and potential mobility in a mining soil under dynamic redox-conditions. - Sci. Total Environ. 624: 1059-1071.

[11] Hamid, Y., Lin, T., Wang, X., Bilal, H., Muhammad, Y., Muhammad, Z. A., Xiaoe, Y. (2018): Immobilization of cadmium and lead in contaminated paddy field using inorganic and organic additives. - Scientific Reports 8: 17839. DOI: 10.1038/s41598-018-35881-8. 
[12] Hamid, Y., Tang, L., Yaseen, M., Hussain, B., Zehra, A., Aziz, M. A., He, Z. L., Yang, X. (2019a): Comparative efficacy of organic and inorganic amendments for cadmium and lead immobilization in contaminated soil under rice-wheat cropping system. Chemosphere 214: 259-268.

[13] Hamid, Y., Tang, L., Muhammad, I. S., Xuerui, C., Hussain, B., Aziz, M. A., Muhammad, U., He, Z. L., Yang, X. (2019b): An explanation of soil amendments to reduce cadmium phytoavailability and transfer to food chain. - Sci. Total Environ. 660: 80-96.

[14] Hamid, Y., Tang, L., Lu, M., Bilal, H., Afsheen, Z., Muhammad, B. K., Zhenli, H., Hanumanth, K. G., Xiaoe, Y. (2019c): Assessing the immobilization efficiency of organic and inorganic amendments for cadmium phytoavailability to wheat. - J. Soils Sed. https://doi.org/10.1007/s11368-019-02344-0.

[15] Hong, C. O., Lee, D. K., Kim, P. J. (2008): Feasibility of phosphate fertilizer to immobilize cadmium in a field. - Chemosphere 70: 2009-2015. DOI: 10.1016/j.chemosphere.2007.09.025.

[16] Hong, C. O., Doug, Y. C., Do, K. L., Pil, J. K. (2010): Comparison of phosphate materials for immobilizing cadmium in soil. - Arch. Environ. Contam. Toxicol. 58: 268274. DOI: $10.1007 / \mathrm{s} 00244-009-9363-2$.

[17] Hu, W., Zhang, Y., Huang, B., Teng, Y. (2017): Soil environmental quality in greenhouse vegetable production systems in eastern China: current status and management strategies. - Chemosphere 170: 183-195.

[18] Igalavithana, A. D., Eilhann, E. K., Meththika, V., Jörg, R., Deok, H.M., Erik, M., Daniel, C. W. T., Yong, S. O. (2019): Soil lead immobilization by biochars in short-term laboratory incubation studies. - Environ. Internation. 127: 190-198.

[19] Khan, M. A., Khan, S., Ding, X., Khan, A., Alam, M. (2018): The effects of biochar and rice husk on adsorption and desorption of cadmium on to soils with different water conditions (upland and saturated). - Chemosphere 193: 1120-1126.

[20] Lahori, A. H., Zhang, Z. Q., Guo, Z. Y., Mahar, A., Li, R. H., Awasthi, M. K., Sial, T. A., Kumbhar, F., Wang, P., Shen, F., Zhao, J. C., Huang, H. (2017): Potential use of lime combined with additives on (im)mobilization and phytoavailability of heavy metals from $\mathrm{Pb} / \mathrm{Zn}$ smelter contaminated soils. - Ecotox. Environ. Saf. 145: 313-323.

[21] Leng, L. J., Xu, X. W., Wei, L., Fan, L. L., Huang, H. J., Li, J. A., Lu, Q., Li, J., Zhou, W. G. (2019): Biochar stability assessment by incubation and modelling: methods, drawbacks and recommendations. - Sci. Total Environ 664: 11-23.

[22] Li, H., Shi, W. Y., Shao, H. B., Shao, M. A. (2009): The remediation of the lead polluted garden soil by natural zeolite. - J. Hazard. Mater. 169: 1106-1111.

[23] Li, H. S. (2000): Principle and Technology of Plant Physiological and Biochemical Experiment. - Higher Education Press, Beijing (in Chinese).

[24] Li, Y. L., Cheng, J. Z., Lee, X., Chen, Y., Gao, W. C., Pan, W. J., Tang, Y. (2019): Effects of biocharbased fertilizers on nutrient leaching in a tobacco-planting soil. - Acta Geochimica 38: 1-7.

[25] Liang, X., Yi, X., Yingming, X., Pengchao, W., Lin, W., Yuebing, S., Qingqing, H., Rong, H. (2016): Two-year stability of immobilization effect of sepiolite on Cd contaminants in paddy soil. - Environ. Sci. Pollut. Res. 23: 12922-12931. https://doi.org/10.1007/ s11356-016-6466-y.

[26] Liu, K., Lv, J., He, W., Zhang, H., Cao, Y., Dai, Y. (2015): Major factors influencing cadmium uptake from the soil into wheat plants. - Ecotoxicol. Environ. Saf. 113: 207213.

[27] Ma, L., Xu, R., Jiang, J. (2010): Adsorption and desorption of $\mathrm{Cu}$ (II) and $\mathrm{Pb}$ (II) in paddy soils cultivated for various years in the subtropical China. - Environ Sci. 22: 689695. 
[28] Mahar, A., Wang, P., Li, R., Zhang, Z. (2015): Immobilization of lead and cadmium in contaminated soil using amendments: a review. - Pedosphere 25: 555-568. http:// dx.doi.org/10.1016/S1002-0160(15)30036-9.

[29] Méndez, A., Terradillos, M., Gascó, G. (2013): Physicochemical and agronomic properties of biochar from sewage sludge pyrolysed at different temperatures. - J. Anal. Appl. Pyrolysis. 102: 124-130.

[30] Ok, Y. S., Chang, S. X., Gao, B., Chung, H. J. (2015): SMART biochar technology-a shifting paradigm towards advanced materials and healthcare research. - Environ. Technol. Innov. 4: 206-209.

[31] Park, J. H., Lamb, D., Paneerselvam, P., Choppala, G., Bolan, N., Chung, J. W. (2011): Role of organic amendments on enhanced bioremediation of heavy metal (loid) contaminated soils. - J. Hazard. Mater. 185: 549-574.

[32] Qiu, Z., Chen, J., Tang, J., Zhang, Q. (2018): A study of cadmium remediation and mechanisms: improvements in the stability of walnut shell-derived biochar. - Sci. Total Environ 636: 80-84. https://doi.org/10.1016/j.scitotenv.2018.04.215.

[33] Rehman, M. Z., Hinnan, K., Fatima, A., Shafaqat, A., Muhammad, R., Muhammad, F. Q., Muhammad, I., Muhammad, U. K., Muhammad, A. (2017a): Effect of limestone, lignite and biochar applied alone and combined on cadmium uptake in wheat and rice under rotation in an effluent irrigated field. - Environ. Pollut. 227: 560-568.

[34] Rehman, M. Z., Muhammad, R., Shafaqat, A., Muhammad, S., Muhammad, I. S. (2017b): Contrasting effects of organic and inorganic amendments on reducing lead toxicity in wheat. - Bull. Environ. Contam. Toxicol. 99: 642-647. DOI: 10.1007/s00128017-2177-4.

[35] Rodríguez-Vila, A., Asensio, V., Forjánand, R., Covelo, E. F. (2015): Chemical fractionation of $\mathrm{Cu}, \mathrm{Ni}, \mathrm{Pb}$ and $\mathrm{Zn}$ in a mine soil amended with compost and biochar and vegetated with Brassica juncea L. - J. Geochem. Explor. 158: 74-81.

[36] Schweizer, S. A., Seitz, B., van der Heijden, M. G. A., Schulin, R., Tandy, S. (2018): Impact of organic and conventional farming systems on wheat grain uptake and soil bioavailability of zinc and cadmium. - Sci. Total Environ. 639: 608-616.

[37] Shaha, S. C., Abul, M. K., Osman, T. K. (2012): Effect of lime and farmyard manure on the concentration of cadmium in water spinach (Ipomoea aquatica). - ISRN Agronomy 6. DOI: 10.5402/2012/719432 (2012).

[38] Shen, Z. T., Zhang, Y. Y., Jin. F., McMillan. O., Al-Tabbaa. A. (2017): Qualitative and quantitative characterisation of adsorption mechanisms of lead on four biochars. - Sci. Total Environ. 609: 1401-1410.

[39] Shi, L., Zhaohui, G., Fang, L., Xiyuan, X., Chi, P., Peng, Z., Wenli, F., Hongzhen, R. (2019): Effect of liming with various water regimes on both immobilization of cadmium and improvement of bacterial communities in contaminated paddy: a field experiment. Int. J. Environ. Res. Public Health 16: 498. DOI: 10.3390/ijerph16030498.

[40] Shirvani, M., Shariatmadari, H., Kalbasi, M., Nourbakhsh, F., Najaf, B. (2006): Sorption of cadmium on palygorskite, sepiolite and calcite: equilibria and organic ligand affected kinetics. - Colloids and Surfaces A: Physicochem. Engin. Aspects 287: 182-190.

[41] Simón, M., Diez, M., González, V., García, I., Martín, F., de Haro, S. (2010): Use of liming in the remediation of soils polluted by sulphide oxidation: a leaching-column study. - J. Hazard. Mater. 180: 241-246.

[42] Singh, J., Kalamdhad, A. S. (2013): Effects of lime on bioavailability and leachability of heavy metals during agitated pile composting of water hyacinth. - Bioresour. Technol. 13: 148-155.

[43] Song, W., Guo, M. (2012): Quality variations of poultry litter biochar generated at different pyrolysis temperatures. - J. Anal. Appl. Pyrolysis 94: 138-145.

[44] Sui, F., Zuo, J., Chen, D., Li, L., Pan, G., Crowley, D. E. (2018): Biochar effects on uptake of cadmium and lead by wheat in relation to annual precipitation: a 3-year field 
study. - Environ. Sci. Pollut. Res. 25: 3368-3377. https://doi.org/10.1007/ s11356-017$0652-4$.

[45] Sun, J., Lian, F., Liu, Z., Zhu, L., Song, Z. (2014): Biochars derived from various crop straws: characterization and Cd(II) removal potential. - Ecotoxicol. Environ. Saf. 106: 226-231.

[46] Tessier, A., Campbell, P. G. C., Bisson, M. (1979): Sequential extraction procedure for the speciation of particulate trace metals. - Anal Chem. 51: 844-851.

[47] Tian, T., Ali, B., Qin, Y., Malik, Z., Gill, R. A., Ali, S., Zhou, W. (2011): Alleviation of lead toxicity by 5 -aminolevulinic acid is related to elevated growth, photosynthesis, and suppressed ultrastructural damages in oilseed rape. - Biomed. Res. Int. 1-11.

[48] Wang, Y., Fang, Z. Q., Liang, B., Tsang, E. P. (2014): Remediation of hexavalent chromium contaminated soil by stabilized nanoscale zero-valent iron prepared from steel pickling waste liquor. - Chem. Eng. J. 247: 283-290.

[49] Wiszniewska, A., Hanus-Fajerska, E., Muszyńska, E., Ciarkowska, K. (2016): Natural organic amendments for improved phytoremediation of polluted soils: a review of recent progress. - Pedosphere 26: 1-12.

[50] Wu, Y. J., Zhou, H., Zou, Z. J., Zhu, W., Yang, W. T., Peng, P. Q., Zeng, M., Liao, B. H. (2016): A three-year in-situ study on the persistence of a combined amendment (limestone sepiolite) for remedying paddy soil polluted with heavy metals. - Ecotoxicol Environ. Saf. 130: 163-170.

[51] Xiong, Z., Junqing, Z., Peng, C., Wenli, C., Qiaoyun, H. (2019): Bio-organic stabilizing agent shows promising prospect for the stabilization of cadmium in contaminated farmland soil. - Environ. Sci. Pollut. Res. https://doi.org/10.1007/s11356-019-05619-8.

[52] Yan, Y., Yi, Q. Z., Cheng, H. L. (2015): Evaluation of phosphate fertilizers for the immobilization of $\mathrm{Cd}$ in contaminated soils. - PLoS ONE 10: e0124022. DOI: 10.1371/journal. pone.0124022.

[53] Yan-bing, H., Huang, D. Y., Zhu, Q. H., Wang, S., Liu, S. L., He, H. B., Zhu, H. H., Xu, C. (2017): A three-season field study on the in-situ remediation of Cd-contaminated paddy soil using lime, two industrial by-products, and a low-Cd accumulation rice cultivar. - Ecotoxicol. Environ. Saf. 136: 135-141.

[54] Zhao, Z., Jiang, G., Mao, R. (2014): Effects of particle sizes of rock phosphate on immobilizing heavy metals in lead zinc mine soils. - J. Soil Sci. Plant Nutrition 14: 258266.

[55] Zhu, Q. H., Huang, D. Y., Zhu, G. X., Ge, T. D., Liu, G. S., Zhu, H. H., Liu, S. L., Zhang, X. N. (2010): Sepiolite is recommended for the remediation of Cd-contaminated paddy soil. - Acta Agric. Scand. B. 60: 110-116. 